\title{
AC 2009-1083: A MODEL FOR THE PLANNING, MARKETING, AND IMPLEMENTATION OF A DEPARTMENTAL LAPTOP INITIATIVE
}

\section{Mark Bannatyne, Indiana University-Purdue University, Indianapolis}

Dr. Bannatyne is a Professor of Computer Graphics Technology at the Purdue School of Engineering at IUPUI, and acting Department head for the Department of Design and Communication Technology. Dr. Bannatyne is a graduate of the British Columbia Institute of Technology where he studied Machine Tool Technology, Utah State University (BSc., 1988, MSc. 1992), and Purdue University (Ph.D., 1994). Dr. Bannatyne is an active member of AVA, ITEA, ASEE, Phi Kappa Phi, and Epsilon Pi Tau where he is a member of The Board of Editors for The Journal of Technology Studies. Dr. Bannatyne is also very active in international work and has spoken extensively throughout the United States, Israel, and Russia on the subject of technology's impact in society, the historical aspects of social change due to technology, and computer education courses in the republics of the former Soviet Union.

\section{Dan Baldwin, Indiana University-Purdue University, Indianapolis}

Dan Baldwin is an Assistant Professor of Computer Graphics Technology at IUPUI. Before joining the Purdue School of Engineering and Technology Dan worked as an award-winning freelance illustrator and designer. Dan currently teaches courses in illustration, graphic design, and interactive design and enjoys helping his students gain real world exposure in the classroom through service learning. Dan holds a Masters of Fine Arts in Illustration from the Savannah College of Art and Design.

\section{Kevin Marshall, Indiana University-Purdue University, Indianapolis}

Kevin Marshall currently splits his time between Director of Computer Graphics Technology for the Purdue School of Engineering \& Technology, IUPUI and running his own interactive media company, Rocket Interactive. As the Director of Computer Graphics Technology for IUPUI, he specializes in the study of computer animation techniques and applications and enjoys teaching the latest in animation technology as well as helping his students develop a firm foundation of proper animation principles. 


\title{
A Model for the Planning, Marketing and Implementation of a Departmental Laptop Initiative
}

\begin{abstract}
Students of today are immersed in the culture of mobile technology and the laptop has become a center of connectivity to their world around them, and its use a fundamental means of social and academic success. This wide-use of mobile technology among students has presented a favorable opportunity to employ a laptop program into the undergraduate curriculum.

Until recently, the notion of a mandatory laptop program has been limited due to the high price of hardware and software packages. Laptops have long been considered a preferred portable workstation solution, but the cost was prohibitive, especially to students. Due to advances in manufacturing, technology and competition among vendors the financial burden of purchasing and maintaining a laptop has dramatically decreased. Therefore, after years of discussion, the opportunity to implement a laptop program is now viable.
\end{abstract}

This paper will discuss the model used by the authors to create a laptop initiative for all undergraduate students in the Department of Design and Communication Technology at Indiana University - Purdue University Indianapolis. This paper will focus upon the marketing plan and implementation of the first mandatory laptop endeavor of the School of Engineering Technology. Discussion will include the benefits and rewards of such a program to the institution and student, the planning and assessment of the initiative.

\section{The Need for a Laptop Program: Background for Implementing Success}

Organized laptop programs in higher education date as far back as 1988 when Drew University in Madison, New Jersey, began providing notebook computers (paid for from tuition) to all incoming freshmen. Now more than 50 post-secondary institutions worldwide require at least some of their students to use laptops ${ }^{1}$. In the case of Indiana University-Purdue University Indianapolis (IUPUI), the need for a laptop program came from a perfect alignment of potential student technological growth, a dropping price point for the hardware, and a need to circumvent the previous model of school funded lab equipment which consistently fell behind industry in relevance and standard hardware requirements.

Several studies suggest educational benefits related to laptop use. Specific benefits noted include increased student motivation ${ }^{2}$, a shift toward more student-centered classroom environments ${ }^{3}$, and better school attendance than students not using laptops ${ }^{4}$. At IUPUI, or any institution of higher learning, one can point to an ongoing need for both student motivation and better attendance in the classroom. One serious effect of the outmoded technology in the labs was revealed when students voiced a concern for the quality of instruction via semester ending student evaluations that were highly critical of the lack of laboratory technology. Attendance and student utilization of these labs dropped considerably once it was discovered that the equipment could no longer keep pace with current software needs. For this particular graphics program, the state of technology in the computer labs was crucial for the success of the core curriculum. The 
computer graphics curriculum has many rigors, perhaps none more important than sustaining a learning environment with contemporary technology.

In all disciplines, it is crucial that students possess access to the latest technology whether it is in the form of hardware, such as faster processing computers, or software with features being utilized in industry. It is these business trends and market forces that push the necessity of updated technology. Research supports the contention that technology infused into the classroom increases student expertise in work-force skills. ${ }^{5}$ Even its most basic use, taking lecture notes on their computers, has been shown to help high school graduates improve their proficiency at accessing, evaluating, and communicating information ${ }^{6}$, skills essential in every career.

This perceived lapse in technological upgrades to the laboratories brought forth the discussion on how best to continue forward: maintain the practice of upgrading to the latest technology only when the budget allowed, or consider alternative solutions. Fortunately the price and performance of laptops had reached a point where replacing laboratory desktops with them became a viable solution. It should be noted that while other institutions could make the switch to laptops easier, the authors' department, due to its inherent field of study, had to ensure that laptop performance had reached if not surpassed the critical stage of desktop replacements. For other institutions and departments this was not crucial. Most curricular plans of study, typically where only presentations, light research and word processing are needed, did not depend on powerful computing platforms. In the Department of Design and Communication Technology (DCT) at IUPUI, 3d Animation, multimedia design and video production necessitated the need for actual desktop replacements.

\section{Planning and Assessment}

Once it was determined that desktop replacement was possible through the availability of relatively cheaper and faster laptops, coupled with the additional benefits of retention, and personal ownership of technology, the laptop initiative was formed. For other institutions looking to develop a similar program, it should be noted that there are many ways to implement laptops in the classroom. Currently, there are four models for implementing a laptop program. ${ }^{7}$ These are:

- Required but not provided: setting a minimum standard or specifying a particular model of laptop and letting students make their own arrangements for purchase or lease

- Provided by program: distributing laptops to students within a particular program or programs

- Provided in phases: distributing laptops to all first-year students

- Provided in full: distributing laptops to an entire campus at once

Along with the departmental faculty, an advisory board was formed to look at all aspects of these various nodes of implementation. Along with the four existing models to be evaluated, careful consideration was taken with regard to the impact upon students and student learning. One of the first concerns discussed by members of the board was the potential financial consequence for the students. 
Partnerships between schools, nonprofit organizations, and corporations can defray costs, but ultimately parents share the expense with schools that hope to put a laptop in the hands of every child. ${ }^{8}$ Whereas this model is based upon K-12 education, the implications at the collegiate level are similar and frequently related to student funds and tuition loans. While it is true that parents purchase laptops for some students, this is an occurrence more commonly witnessed for incoming freshman rather than upper-level undergraduates.

For this reason, there was a concern among some members of the implementation board that shifting the burden of technology from the university to the individual student might be construed as financially unjust. This stems from a common line of thinking that laptop programs may worsen technology inequities among students for families who are unable to assume these costs. ${ }^{9}$ When evaluating the four models for laptop programs, financial burden was a key factor in choosing the required but not provided model. The advisory board believed this to be the best option to ensure success for the students and ultimately the program itself. A minimum requirement for processing speed, display dimensions and RAM was created to help students maximize their investment based upon personal budgets. If a student had already purchased a laptop previous to this initiative and it met the minimum requirements then its utilization was accepted into the program.

Interestingly, the authors discovered during this process that the application of student financial aid towards the purchase of a laptop was less difficult if it was, indeed, a requirement of the department. Therefore, the mere act of requiring departmental laptops was hugely beneficial to students who utilized loans to defray the cost of the technology. Without this stipulation, students interested in buying a laptop had to traverse complicated measures to employ educational loans in this fashion. Some loans would not, in fact, grant funding for laptops if they were not an official requirement of their education.

While financial considerations were being finalized, several members of the advisory board researched programs that shared similar curricular outcomes. Specifically, the use of technology in the laboratories was identified. It was soon discovered that many institutions were in a similar predicament with regards to lab updates versus laptops.

\section{Marketing}

After examination of other institutions' initiatives, one early discovery revealed that little, if any, effort was made to market, inform or educate the student population in conjunction with the launch of a laptop program. The authors commonly saw most programs simply mandate the policy with the expectation that students would simply adapt. For the DCT laptop program to succeed and progress smoothly, a concerted effort to brand and market the initiative was deemed important. After all, most students are aware of multimedia ad campaigns that promote the benefits of particular products or services. The laptop initiative was to be no different.

With the beginning of the fall 2008 semester in mind for the official launch of the laptop program, and some research into current design trends aimed at this particular market segment (male and female, ages 18-22), an overarching logo, theme and message was developed. The message was based upon the aforementioned student discontent, and was crafted to align the 
laptop initiative directly with the students desire for better classroom technology. The message, therefore, was simple: "Put the power back in the hands of the people!" The entire campaign was designed from the perspective of the students, and served as a call to action where they would not only support and embrace the change, but also lead the revolution. Injecting modern sensibilities into the context of traditional propaganda posters provided a vehicle for further promotional development.

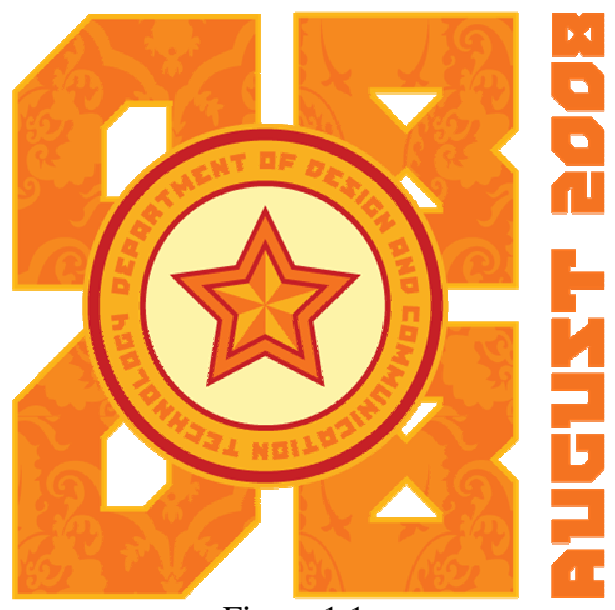

Figure $1.1-$

Main Logo Concept Promoting Date of Launch

A series of posters was created featuring custom illustrations based upon the logo theme (Figure 1.1). Three designs were developed and released individually over the span of six months, each one generating interest and adding more specific information about the laptop program. RISE!, REALIZE! and REJOICE! were chosen to be the main tagline of each poster. With these three words the intention was to energize the audience, build awareness of the brand initiative, and communicate the overall message sequentially. The first promotional poster, RISE! (Figure 1.2), was released in March 2008 and was designed intentionally void of too many initiative details to better stage intrigue among students. This poster was followed in May 2008 by the second design, REALIZE! (Figure 1.3), that added more program information and further developed the central theme. This poster was released shortly before finals week of the spring semester, and like the other posters placed throughout the building and laboratories. The third and final poster design (Figure 1.4) was released in August 2008 gives the final call to "REJOICE!" and enjoy the multiple benefits of participating in the program. 


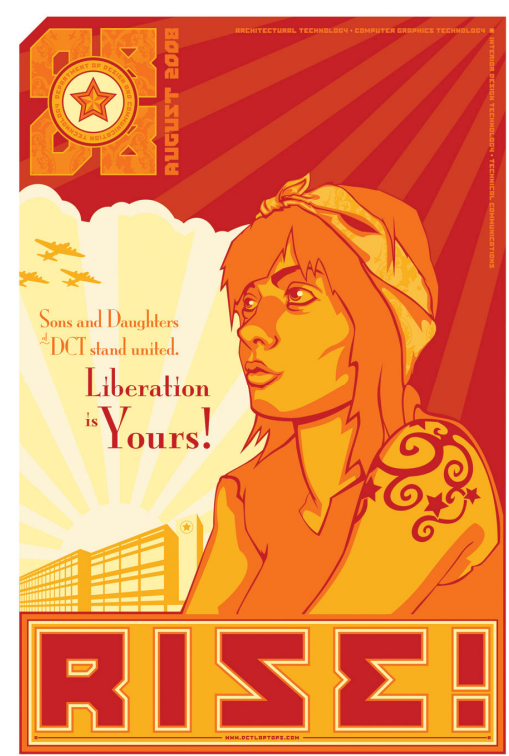

Figure $1.2-$

Poster Design 1/3 released March 2008

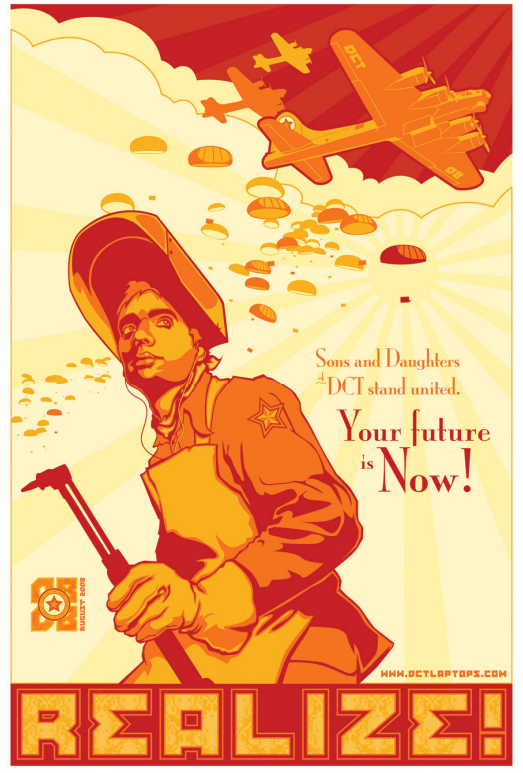

Figure $1.3-$

Poster Design 2/3 released May 2008 


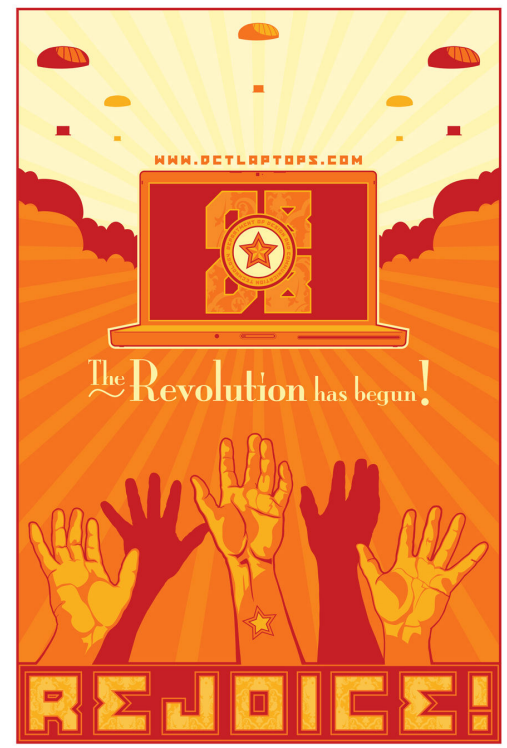

Figure $1.4-$

Poster Design 3/3 released August 2008

In addition to the printed pieces for static display on walls, a cyber strategy was implemented to aid in the promotion and presentation of information regarding the program. A departmental specific domain name was created from which to host a website containing laptop program information. This website was created in the theme developed from the print collateral as to establish continuity in each medium and was released on the same March day as the first poster. Downloadable .pdf files for each specific program were created that enabled students to print and accompany them to the store when deciding on which laptop to purchase. Links regarding specific software titles, university discounts from various vendors and a list of Frequently Asked Questions were posted on this website.

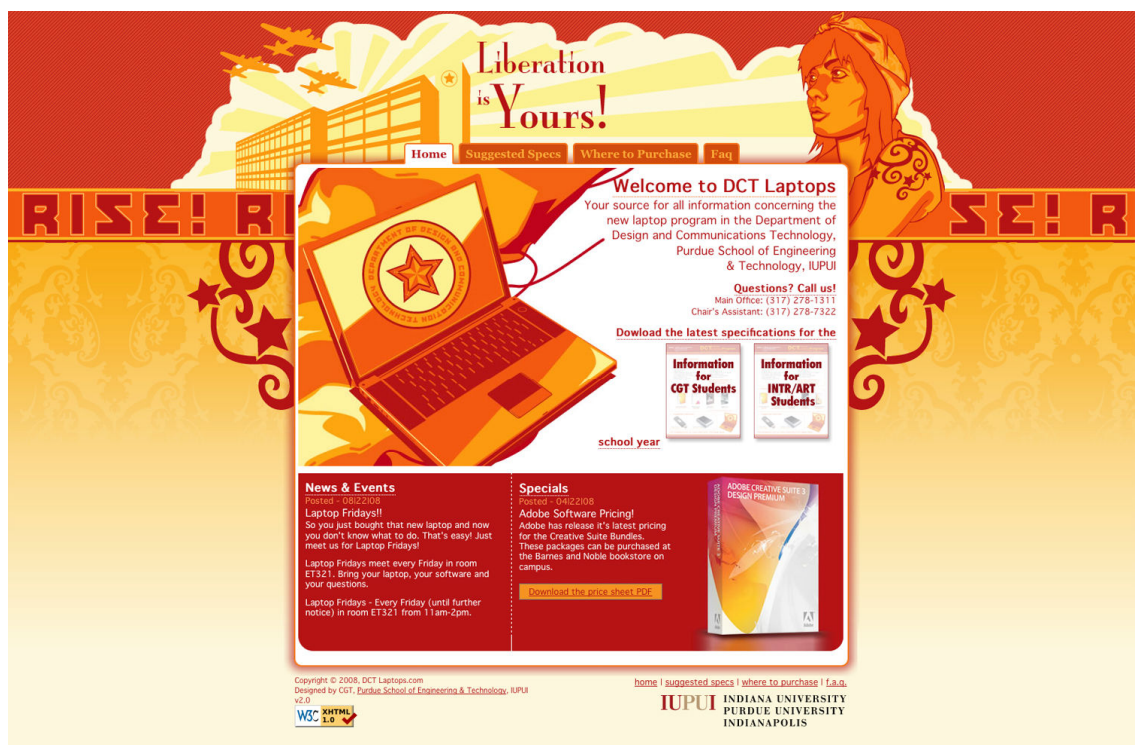

Figure 1.5 -

Promotional Website Design 


\section{Implementation}

Implementation of the laptop program took place on the first day of the fall 2008 semester after the successful advertising campaign. The overall campaign allowed sufficient time for purchase decisions and financial solutions, and the marketing efforts combined with the online informational presence aided the smooth transition from traditional desktop laboratories to laptop specific labs.

Several outdated labs were retrofitted with power supply and networking peripherals and cleared to maximize the workspace. For some laboratories this meant removal of the old equipment and a rearranging of work areas. Removing outdated equipment in these labs, created a more open workspace which in turn led to further improved student morale and a positive perception of the laptop program itself. IUPUI was also in the midst of updating all of the wireless access points throughout campus in an effort to embrace mobile computing. No longer would students feel the need to stay within the confines of a lab or classroom when they could now identify more comfortable work areas as they study, develop projects or work with peers.

In an effort to show an outward symbol of support and generate value in the laptop program to the students, the department opened a library, populated with course textbooks. The departmental library was seen as a positive benefit. Several textbooks for each course were available for checkout, helping to alleviate any additional financial burden to the students.

Additionally, there was an effort to reduce the cost of required software, purchased by the students for their coursework. It was discovered that depending on the sequence of offered courses, some software needs could be kept to a minimum, thereby creating an added financial benefit. Therefore the first two years of curriculum were aligned, where possible, to coincide with a cost effective software bundle. For incoming freshmen, this management of course structure, software concerns and library benefits assisted in considerable financial savings.

\section{Progress}

\section{Positive}

In the current and initial year of implementation, the laptop program has fostered quite favorable results. Student morale, reflected in course evaluations where laptop instruction occurred, has improved. Students now have the resources in hand to work at their own pace and are free to work between classes at a preferred location. The authors believe that these factors have led to an increase in coursework quality and obvious enhancement of attitude.

In the Computer Graphics Technology program at IUPUI, it is common for group projects to be assigned in several courses. Prior to the laptop program it was difficult for students to participate in these projects. Lack of lab space or scheduling conflicts made it difficult for students to find adequate working space or arrange a time to meet and work. With individual ownership of extremely mobile technology, these group projects have become more productive. Of course, this 
was of no surprise to the authors since the earlier findings from other universities predicted this outcome. Studies of several different technology-integrated classrooms revealed two main findings: Group work with technology available

- Increased the amount of information available to individual students due to inter- and intra-group sharing and

- Enhanced critical thinking because the group members have to learn how to sift through conflicting information and ideas from several different sources. ${ }^{10}$

In addition to the aforementioned benefits to the students, the authors would be remiss to not mention the benefits to the faculty. With the inclusion of the laptop program, laboratory exercises and demonstrations have improved. Faculty now has the ability to demonstrate new technologies and software applications in the classroom. This freedom circumvented prior security and permissions issues that often limited the university managed desktop computers in past labs.

Negative

For the most part the laptop program can be deemed a success in that it has proven itself to be a benefit to both student and instructor. With the rewards, however, there have been issues amidst this first year implementation that merit discussion. Networked printers have, at times, become temperamental when students with various operating systems attempt to print. In response, the laptop advisory board has developed a document that details the process. This aid has been included in all class syllabi where laptop use occurs. A few courses have specific software titles that require the Windows OS for use. Those students that entered the program with Apple laptops have been affected. In response to this unforeseen situation, the laptop advisory board created an even entitled "Laptop Fridays" where demonstrations on how to create duel boot or virtualization environments took place. A slight disruption over the first two weeks of the semester, these events quickly allowed students to remain current with their required coursework.

Faculty concern has developed with regard to managing the knowledge base associated with varying laptop models and manufacturers. With the variety of laptops present in any given laboratory, there has been a small but noticeable burden placed upon the instructors to help troubleshoot various software and hardware issues. This concern, along with managing student laptop etiquette, represents opportunities to overcome challenges essential for continued success.

\section{Current Updates}

Software titles originally factored in as a cost burden to the student have now nearly been removed all together. A historic, and first of its kind, software licensing agreement with Adobe, a major software developer, and IUPUI has allowed the total cost of student laptop ownership to drop by $25 \%$. This unforeseen benefit has allowed the department to heavily promote the benefits of laptop ownership as opposed to traditional desktop lab environments. 
Negotiations with several vendors have begun in attempts to manage cost while removing some of the frustration and confusion in the purchase process. It has been determined that an onsite repair facility can be implemented for a nominal startup cost and carries the substantial benefit of providing some level of profit to the school.

After nearly a full academic year with the laptop program in place, the focus has now shifted to the visual appeal and ergonomic layout of the laboratories themselves. The authors believe that the labs themselves can evolve into a more aesthetically pleasing and productive work environment that does not resemble the academic "look and feel" of a traditional computer lab.

\section{Reflection and Conclusion}

As with any new venture there are bound to be a plethora of setbacks as well as successes. The described laptop initiative is no different. Each week provides varying feedback from students and faculty alike concerning favorable outcomes as well as the occasional technological issues that may arise. After seven months, it is clear, however, that an overwhelming majority of students prefer this new model of academic technology, moreover the learning environment it creates. The freedom this model presents, the level of instruction it supports and the overall act of individual ownership has helped build a progressive program that will continue to look forward rather than back.

\section{Bibliography}

1. Brown, R. (1998). Notebook universities: Creating a technology-intensive learning environment. URL: http://horizon.unc.edu/TS/cases/1998-05.asp (retrieved January 11, 2009).

2. Rockman, S., Walker, L. and M. Chessler (1998). Powerful tools for schooling: Second year study of the laptop program. A project for Anytime Anywhere Learning by Microsoft Corporation. URL: http://www.microsoft.com/education/download/aal/research2.rtf (retrieved January 7, 2009).

3. Stevenson, K. R. (1998). "Evaluation report-Year 2: Schoolbook laptop project." Beaufort County School District: Beaufort, S.C. URL: http://www.beaufort.k12.sc.us/district/ltopeval.html (retrieved December 14, 2008).

4. $\quad$ Stevenson, K. R. (1999). Learning by laptop. "School Administrator," 56(4), 18-21.

5. Cradler, J. (1994). Summary of Research and Evaluation Findings Relating to Technology in Education (San Mateo, Calif.: Educational Support Systems. http://www.wested.org/techpolicy/refind.html (retrieved December 22, 2008).

6. $\quad$ Peck, K. L. and D. Dorricott. (1994). "Why Use Technology?" Educational Leadership, Vol. 51, No. 7, April 1994, pp. 11-14. URL: http://www.ascd.org/cms/objectlib/ascdframeset/index.cfm? publication=http://www.ascd.org/publications/ed_lead/199404/toc.html (retrieved January 14, 2009).

7. The Node Learning Technologies Network (1999, Spring). LTReport: The laptop college. URL: http://thenode.org/ltreport/issues.cfm (retrieved January 4, 2009).

8. Wishengrad, R. (1999). Are paper textbooks ready to fold? "The Education Digest," 64(6), 57-61 
9. Jameson, R. (1999). Equity and access to educational technology. "Thrust for Educational Leadership," 28(4), 28-31.

10. J. H. Sandholtz, C. Ringstaff, and D. C. Dwyer. (1997). Teaching with Technology: Creating StudentCentered Classrooms (New York: Teachers College Press). 